\title{
Anatomical correlates of visual and tactile extinction in humans: a clinical CT scan study
}

\author{
Giuseppe Vallar, Maria Luisa Rusconi, Lorenzo Bignamini, Giuliano Geminiani, \\ Daniela Perani
}

\begin{abstract}
The anatomical correlates of tactile and visual extinction with double simultaneous stimulation were investigated in a series of 159 patients with right brain damage caused by stroke. Forty six patients showed extinction (22 tactile, 14 visual, 10 tactile and visual). Over $50 \%$ of the patients with extinction had deep lesions, which were found in about $25 \%$ of the patients with visuospatial neglect not associated with extinction. In the patients with extinction and cortico-subcortical damage the paraventricular occipital white matter and the dorsolateral frontal cortex were most often involved. By contrast, when neglect was also present, the lesions clustered in the inferior parietal lobule. These data suggest, from an anatomical perspective, that partly different neural mechanisms may underlie neglect and extinction. The comparatively high frequency of subcortical lesions involving the ascending pathways may be a neural correlate of a sensory component of extinction.
\end{abstract}

$(\mathcal{F}$ Neurol Neurosurg Psychiatry 1994;57:464-470)

The term extinction refers to the phenomenon whereby patients with unilateral damage fail to report a stimulus (visual, tactile, or auditory), delivered to the side contralateral to the lesion, when a symmetrical ipsilateral stimulus is given. ${ }^{12}$ Contralateral extinction may be produced by both left-sided or rightsided hemispheric lesions, but a closer association with damage to the right side of the brain has been repeatedly found. ${ }^{3-6}$ Damage involving the parietal lobe has long been considered the anatomical correlate of extinction. ${ }^{278}$ In recent years, however, left tactile and visual extinction has been reported in individual patients with right-brain damage to frontal and subcortical (thalamus, basal ganglia, white matter, and internal capsule) regions. ${ }^{9-13}$ These non-systematic findings closely resemble the neurological pattern of visuospatial neglect that can be produced by various different cortical and subcortical lesion sites, even though a right inferior-posterior parietal lesion is, as classically maintained, the more frequent anatomical correlate. $^{14-16}$ This lesion pattern is consistent with the view that extinction and visuospatial neglect are manifestations of a common underlying deficit. ${ }^{17}$ Such a conclusion may be premature, however, because, unlike extrapersonal neglect, ${ }^{16}$ the anatomical correlates of extinction have never been systematically investigated in a consecutive large series of patients with right-sided lesions. We report the anatomical (CT scan) correlates of visual and tactile extinction, assessed by a standard clinical neurological examination, in a series of 159 patients with right-brain damage as a result of a stroke.

\section{Materials and methods \\ PATIENTS}

A continuous series of 159 patients with rightbrain damage (91 men and 68 women, mean age $62 \cdot 74$ (range 17-87) years) entered this study. All patients had had an ischaemic or haemorrhagic stroke and had no history or evidence of previous cerebrovascular disease, dementia, or psychiatric disorders. They were all examined in a recent phase, within 30 days after stroke onset.

\section{ASSESSMENT}

Patients were given a standard clinical neurological examination to assess motor, somatosensory and visual field deficits. ${ }^{18}$ The procedures used to detect tactile and visual extinction are reported in detail.

\section{Tactile extinction}

Ten single and 10 double symmetrical simultaneous tactile stimuli were given, as shortly and slightly as possible, on the dorsal surface of the patients' hands by the examiner's fingertip. The procedure was repeated in the lower limbs by giving the stimuli on the dorsal surface of the patients' feet. Before examination, patients were warned that stimuli could be single or double and gave a verbal response. Stimuli were given after a fixed random schedule. Patients were classified as showing: (1) extinction if after double stimulation they failed to perceive the stimulus on the left hand, foot, or both in more than $30 \%$ of the trials, but correctly reported more than $80 \%$ of single left and $100 \%$ of single right stimuli; (2) somatosensory deficits if they reported less than $80 \%$ of single or left and $100 \%$ of single right stimuli.

\section{Visual extinction}

The confrontation technique was employed. Patients were required to detect the movement of the examiner's index finger. The upper and lower quadrants were examined separately. Sequence of stimulation, scoring 
Table 1 Number of patients showing tactile extinction, visual extinction, or both, and extrapersonal neglect, with localisation of lesion

\begin{tabular}{lclllll}
\hline Lesion site & $\begin{array}{l}\text { Tactile } \\
\text { extinction }\end{array}$ & $\begin{array}{l}\text { Tactile } \\
\text { extinction } \\
\text { and neglect }\end{array}$ & $\begin{array}{l}\text { Visual } \\
\text { extinction }\end{array}$ & $\begin{array}{l}\text { Visual } \\
\text { extinction } \\
\text { and neglect }\end{array}$ & $\begin{array}{l}\text { Tactile } \\
\text { and visual } \\
\text { extinction }\end{array}$ & Total \\
\hline $\begin{array}{l}\text { Deep } \\
\text { Cortico- }\end{array}$ & 7 & 4 & 4 & 2 & 7 & 24 \\
subcortical & 7 & 3 & 5 & 4 & 3 & 22 \\
Total & 14 & 7 & 9 & 6 & 10 & 46 \\
\hline
\end{tabular}

procedure, and classification of patients as showing contralateral left visual extinction or visual field defects were the same as used for the assessment of tactile extinction and somatosensory deficits.

\section{Extrapersonal visual neglect ${ }^{18}$}

Patients were required to cross out 13 circles (six left-side, one central, six right-side) printed on a $21 \times 29.7 \mathrm{~cm}$ paper. Patients were classified as showing extrapersonal neglect if they omitted to cross out one or more left-side circles.

\section{Anatomical study}

In the patients with damage involving the cortex, lesion site was determined by the method of Damasio and Damasio. ${ }^{19}$ The deep structures involved were localised from the atlas of Matsui and Hirano ${ }^{20}$ and lesion size was determined by the method of Kertesz et al. $^{21}$

\section{Results}

Table 1 gives the number of patients showing tactile extinction, visual extinction, and extrapersonal neglect and the deep $v$ corticosubcortical localisation of the lesion. The global incidence of visual and tactile extinction was $29 \%$ (46 of 159 patients). Extrapersonal neglect, as assessed by the circle cancellation task, was found in 13 of 46 patients with extinction (28\%). The median interval between stroke onset and neuropsychological examination was seven days in the 33 patients with extinction not associated with neglect and nine days in the 13 patients with extinction and neglect.

Twenty four of 46 patients with extinction $(52 \%)$ had lesions confined to deep structures (table 2). The basal ganglia (lenticular nucleus) was the most often damaged structure, followed by the anterior periventricular white matter, the posterior limb, and the genu of the internal capsule. The thalamus was damaged in four patients $(17 \%)$. In five patients $(21 \%)$ the lesion was confined to the white matter, the internal capsule, or both (patients 7, 15, 16, 18, 21). Extrapersonal neglect was present in six patients: in three of the four $(75 \%)$ patients with thalamic lesions $(2,4,20)$, and in three of the $15(20 \%)$ patients with damage to the basal ganglia ( 1 , $3,19)$. The patients with lesions confined to the white matter or the internal capsule did not show extrapersonal neglect. The size of the lesion was comparable among patients with visual extinction, tactile extinction or both $(\mathrm{F}<1 ; \mathrm{df}=2,21 ; \mathrm{NS})$, and between patients with and without hemineglect (unpaired $t$ test: $\mathrm{df}=22 ; t=0.59 ; \mathrm{NS}$ ).

The figure shows the lesion maps of the 22 patients with extinction and cortico-subcortical lesions. Eight of 22 patients (patients $25-32 ; 36 \%$ ) had lesions involving both the prerolandic and postrolandic cortical regions. In patient 27 the lesion was mainly frontal,

Table 2 Localisation and size of the deep vascular lesions in 24 patients with right-brain damage and tactile extinction, visual extinction, or both

\begin{tabular}{|c|c|c|c|c|c|c|c|c|c|c|c|}
\hline \multirow{2}{*}{$\begin{array}{l}\text { Group and } \\
\text { patient no }\end{array}$} & \multirow[b]{2}{*}{$C n$} & \multirow[b]{2}{*}{$L n$} & \multirow[b]{2}{*}{$I$} & \multirow[b]{2}{*}{$T$} & \multicolumn{3}{|l|}{$I C$} & \multicolumn{2}{|c|}{$P V W M$} & \multirow{2}{*}{$\begin{array}{l}\text { Size } \\
\left(\mathrm{cm}^{3}\right)\end{array}$} & \multirow[b]{2}{*}{ Aetiology } \\
\hline & & & & & $A 1$ & Ge & $P 1$ & Ant & Post & & \\
\hline \multirow{2}{*}{\multicolumn{12}{|c|}{$\begin{array}{l}\text { Tactile } \\
\text { extinction: }\end{array}$}} \\
\hline & & & & & & & & & & $14 \cdot 54$ & I \\
\hline $2^{\star}$ & & & & $X-p$ & & & $\mathrm{X}$ & & $\mathrm{x}$ & 2.54 & $\mathrm{H}$ \\
\hline $3 *$ & & $\mathrm{X}$ & & & $\mathrm{X}$ & $\mathrm{X}$ & $\mathbf{x}$ & & & 3.32 & I \\
\hline $\begin{array}{l}4^{\star} \\
5\end{array}$ & & $\mathbf{x}$ & & $\mathbf{X}$ & & $\mathrm{X}$ & $\mathbf{X}$ & & $\mathbf{X}$ & $\begin{array}{l}3.90 \\
0.55\end{array}$ & $\mathbf{H}$ \\
\hline $\begin{array}{l}5 \\
6\end{array}$ & & $\hat{\mathrm{X}}$ & & & & $\mathbf{X}$ & $\mathrm{X}$ & $\mathrm{X}$ & & $\begin{array}{l}2 \cdot 55 \\
5 \cdot 51\end{array}$ & H \\
\hline 7 & & & & & & & & $\mathbf{X}$ & & $2 \cdot 35$ & I \\
\hline $\begin{array}{l}8 \\
0\end{array}$ & & $\mathbf{X}$ & & & & & $\mathbf{x}$ & $\mathbf{x}$ & $\mathbf{x}$ & $16 \cdot 19$ & I \\
\hline $\begin{array}{r}9 \\
10\end{array}$ & $\mathrm{x}$ & $\underset{\mathbf{X}}{\mathbf{X}}$ & & . & $\mathbf{x}$ & $\mathbf{x}$ & & & & $\begin{array}{r}0.59 \\
15.02\end{array}$ & I \\
\hline $\begin{array}{l}10 \\
11\end{array}$ & $x$ & $\mathbf{X}$ & & 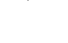 & $\boldsymbol{X}$ & $\mathbf{X}$ & $\mathbf{X}$ & $\mathbf{X}$ & & $\begin{array}{r}15 \cdot 02 \\
4 \cdot 85\end{array}$ & I \\
\hline \multicolumn{12}{|l|}{$\begin{array}{l}\text { Tactile and visual } \\
\text { extinction }\end{array}$} \\
\hline 12 & & $\mathbf{x}$ & & & $\mathbf{x}$ & $\mathbf{X}$ & $\mathbf{x}$ & $\mathbf{X}$ & & $17 \cdot 11$ & $\mathrm{H}$ \\
\hline $\begin{array}{l}13 \\
14\end{array}$ & $\mathbf{X}$ & $\mathbf{x}$ & & & & & & $\mathbf{X}$ & & $\begin{array}{l}7 \cdot 67 \\
1 \cdot 77\end{array}$ & $\begin{array}{l}\mathrm{I} \\
\mathrm{H}\end{array}$ \\
\hline $\begin{array}{l}15 \\
16\end{array}$ & & & & & & & & $\mathbf{X}$ & $\mathbf{y}$ & $4 \cdot 32$ & I \\
\hline $\begin{array}{l}16 \\
17\end{array}$ & & $\mathbf{x}$ & & & $\mathbf{X}$ & $\mathrm{X}$ & $\mathbf{X}$ & $\mathrm{X}$ & $\mathbf{X}$ & $\begin{array}{r}3 \cdot 12 \\
14 \cdot 43\end{array}$ & $\begin{array}{l}1 \\
\mathbf{H}\end{array}$ \\
\hline $\begin{array}{l}18 \\
\text { Visual }\end{array}$ & & & & & & & $\mathbf{X}$ & $\mathbf{X}$ & & $3 \cdot 16$ & I \\
\hline extinction: & & & & & & & & & & & \\
\hline $19^{\star}$ & & $\mathrm{X}$ & $\mathrm{X}$ & & & $\mathbf{X}$ & $\mathbf{x}$ & $\mathbf{X}$ & $\mathbf{x}$ & $7 \cdot 92$ & I \\
\hline $\begin{array}{l}20^{\star} \\
21\end{array}$ & & & & $\mathbf{X}$ & & $\mathbf{X}$ & & $\underset{\mathbf{X}}{\mathbf{X}}$ & & $4 \cdot 13$ & $\mathrm{H}$ \\
\hline $\begin{array}{l}21 \\
22\end{array}$ & & $x$ & & & $\mathrm{X}$ & $\mathbf{x}$ & $\mathrm{x}$ & $\stackrel{\mathbf{x}}{\mathbf{x}}$ & & $\begin{array}{l}1.00 \\
9 \cdot 83\end{array}$ & $\begin{array}{l}\mathrm{I} \\
\mathrm{I}\end{array}$ \\
\hline 23 & & & & $\mathrm{X}$ & & & $\mathbf{x}$ & & & $5 \cdot 51$ & $\mathbf{H}$ \\
\hline 24 & $\mathbf{x}$ & $\mathbf{x}$ & $\mathbf{x}$ & & $\mathbf{x}$ & $\mathbf{x}$ & $\mathbf{x}$ & $\mathrm{x}$ & $\mathbf{x}$ & $30 \cdot 42$ & I \\
\hline $\begin{array}{l}\text { Total } \\
(\%)\end{array}$ & $\begin{array}{l}3 \\
(12)\end{array}$ & $\begin{array}{l}14 \\
(58)\end{array}$ & $\begin{array}{l}2 \\
(8)\end{array}$ & $\begin{array}{l}4 \\
(17)\end{array}$ & $\begin{array}{l}6 \\
(25)\end{array}$ & $\begin{array}{l}10 \\
(42)\end{array}$ & $\begin{array}{l}13 \\
(54)\end{array}$ & $\begin{array}{l}14 \\
(58)\end{array}$ & $\begin{array}{l}7 \\
(29)\end{array}$ & $\begin{array}{l}\text { Mean size } \\
7.57\end{array}$ & \\
\hline
\end{tabular}

*Associated with extrapersonal neglect. $\mathrm{Cn}=$ caudate nucleus; $\mathrm{Ln}=$ lenticular nucleus; $\mathrm{I}=$ insula; $\mathrm{T}=$ thalamus ( $\mathrm{p}=$ posterior); IC = internal capsule (Al, Ge, Pl = anterior limb, genu, posterior limb); PVWM = periventricular white matter; Ant = anterior; Post = posterior; $\mathrm{I}=$ infarction; $\mathrm{H}=$ haemorrhage. 
Figure Lesion maps of 22 patients with corticosubcortical right

hemispheric lesions and extinction: (A) prerolandic and postrolandic lesions; (B) prerolandic lesions; (C) postrolandic lesions.

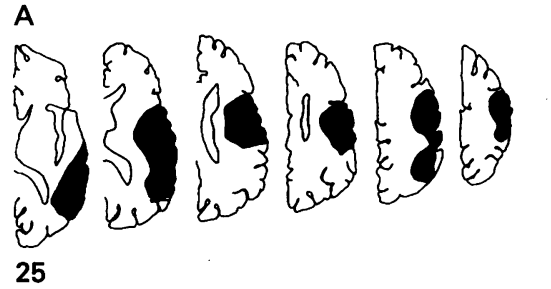

25

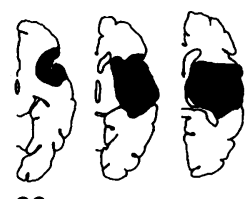

26
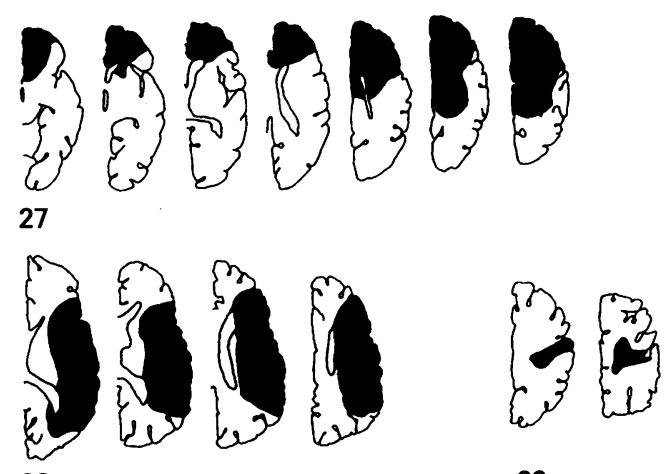

28

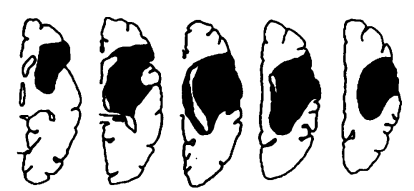

30

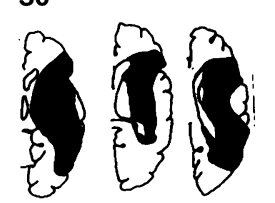

31

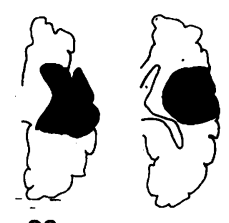

32

\section{B}
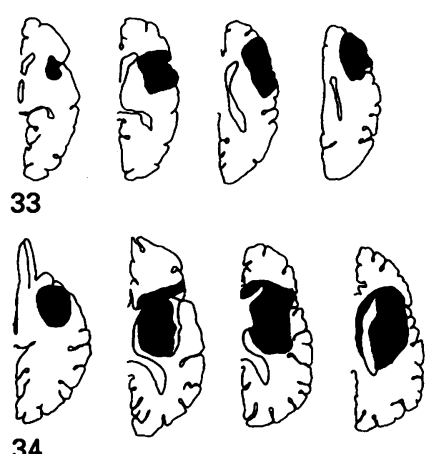

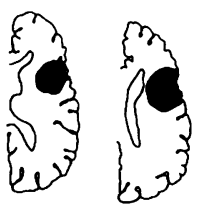

35

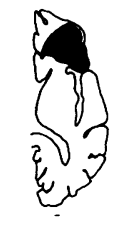

36

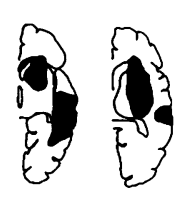

37 with minimal involvement of the parietal white matter. Patient 32 had a frontotemporal lesion also involving the rolandic region. Five patients (33-37; 23\%) had frontal lesions. In patient 37 the lesion involved the anterior-
C

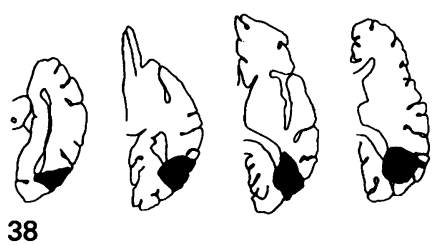

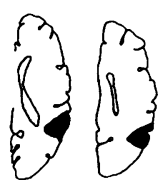

39

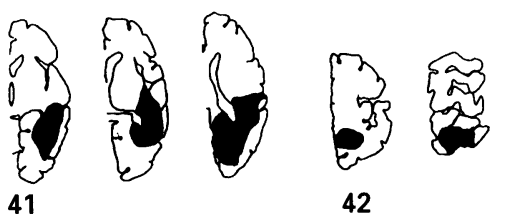

41
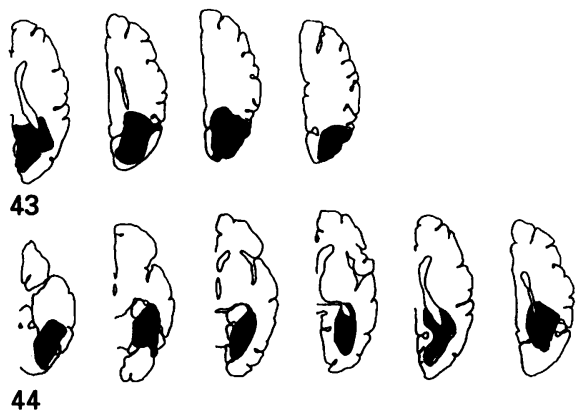

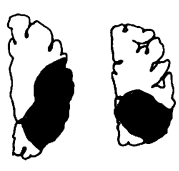

46

superior temporal and basal ganglia regions. Nine patients $(38-46 ; 41 \%)$ had parietooccipital lesions. In patient 46 the rolandic region was marginally involved. Nine patients with cortico-subcortical lesions had visual extinction (25-28, 34, 40-43). In these patients the primary visual areas were spared. Ten patients showed tactile extinction (29-32, 35-37, 44-46), and three patients showed both tactile and visual extinction (33, $38-39)$. In seven patients $(27-28,30-31,34$, $43,46)$ extinction was associated with extrapersonal neglect.

The regions most often involved were determined with reference to the templates of Damasio and Damasio. ${ }^{19}$ In the nine patients with visual extinction, the subcortical paraventricular occipital area was involved in five $(26,28,40,41,43 ; 56 \%)$, the frontal operculum, the premotor and rolandic regions, the middle and superior temporal gyri, and the supramarginal gyrus in four $(44 \%)$. In the 10 patients with tactile extinction, the premotor and rolandic regions were damaged in six $(29-32,35-36 ; 60 \%)$, the middle temporal gyrus in five $(50 \%)$. The inferior parietal lobule (angular gyrus) was involved in two of three patients with visual and tactile extinction (38-39). The supra- 
Table 3 Localisation and size of the deep vascular lesions in 11 patients with right-brain damage and visuospatial neglect not associated with extinction

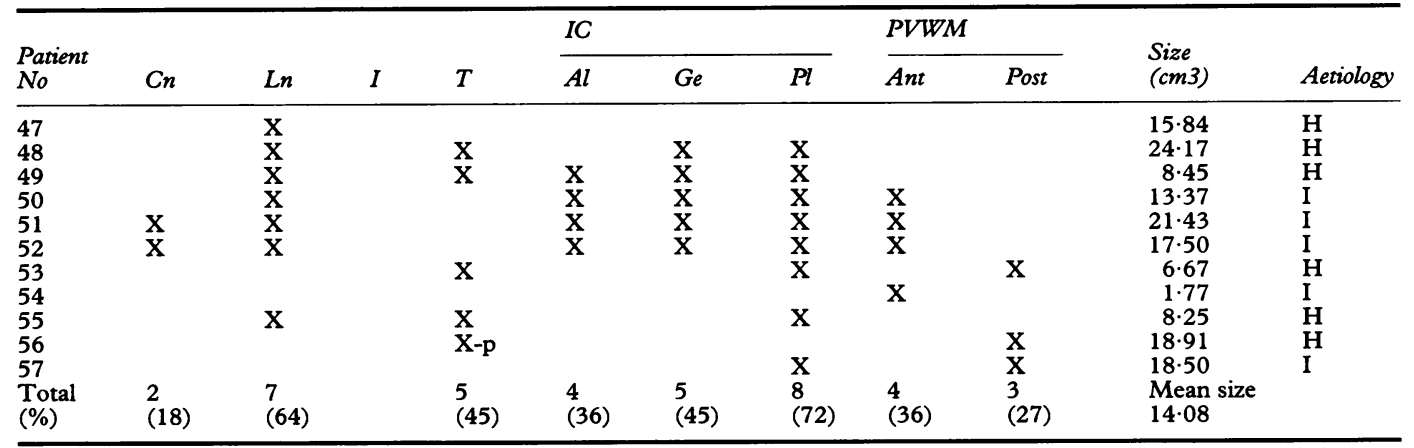

$\mathrm{Cn}=$ caudate nucleus; $\mathrm{Ln}=$ lenticular nucleus; $\mathrm{I}=$ insula; $\mathrm{T}=$ thalamus ( $\mathrm{p}=$ posterior); IC = internal capsule (Al, Ge, $\mathrm{Pl}=$ anterior limb, genu, posterior limb); PVWM = periventricular white matter; Ant = anterior; Post = posterior; $I=$ infarction; $\mathbf{H}=$ haemorrhage.

marginal gyrus of the inferior parietal lobule was damaged in five of seven patients $(71 \%)$, in whom extinction was associated with hemineglect (27 and 30 subcortical, 28, 43, 46). The premotor and rolandic regions, and the paraventricular frontal and occipital areas were damaged in four such patients $(57 \%)$.

The total incidence of extrapersonal neglect was $36 \%$ (58 of 159 patients), in line with previous findings in patients with right-brain damage examined by cancellation tasks. ${ }^{1622}$ Thirteen of the 58 patients with neglect had tactile or visual extinction (lesion sites in table 2 and figure). Thirty eight patients with neglect had left hemianopia and somatosensory deficits, and seven had hemianopia without somatosensory deficits. The median interval between stroke onset and neuropsychological assessment in the 45 patients with neglect not associated with extinction was five days. The lesion of these 45 patients was confined to deep structures in $11(24 \%)$ and cortico-subcortical structures in $34(76 \%)$.

Table 3 shows the localisation and size of the deep lesions of these 11 patients (cases 47-57). Patients with neglect not associated with extinction had, taken as a group, more extensive deep lesions. There are exceptions, however. For instance, patient 24, who showed visual extinction (table 2), had a large lesion involving the basal ganglia, the internal capsule, and the periventricular white matter. Case 54 (table 3), who showed visuospatial neglect not associated with extinction, had a small lesion in the frontal periventricular white matter. An unpaired $t$ test comparing the sizes of the deep lesions of the 18 patients with extinction without neglect (table 2) and of the 11 patients with neglect not associated with extinction showed a significant difference $(\mathrm{df}=27 ; \mathrm{p}=0.046)$. In the 11 cases with neglect without extinction (table 3 ) the structure damaged most often was the posterior limb of the internal capsule (73\%). In these cases the thalamus was more often involved $(45 \%$, table 3$)$ than in the group with extinction ( $17 \%$, table 2$)$.

In the 34 patients with neglect not associated with extinction and corticosubcortical damage, the lesion was anteroposterior in 14 of $34(41 \%)$, posterior in 19 $(56 \%)$, and anterior in one $(3 \%)$. The associa- tion between hemineglect and corticosubcortical (mainly posterior) right sided lesions replicates previous findings. ${ }^{15} 16$ In Vallar and Perani's series of 47 patients with recent rightbrain damage and with neglect (mean interval between stroke onset and neuropsychological assessment 6.6 days), 34 patients $(72 \%)$ had cortico-subcortical lesions as assessed by CT scan; 13 cases $(28 \%)$ had deep lesions. ${ }^{23}$ Similarly, in the series of Cappa et al of chronic right-brain-damaged patients with neglect examined five months after stroke onset, 19 of 24 cases (79\%) had cortico-subcortical lesions, five cases (21\%) deep lesions. ${ }^{24}$ This association between hemineglect and cortico-subcortical lesions is opposite to the case of extinction. Eighteen of 33 patients with extinction without neglect (55\%) had deep lesions (table 1), which were found only in 11 of 45 patients with neglect without extinction $(24 \%)\left(\chi^{2}=7 \cdot 39 ; \mathrm{df}=1\right.$; $\mathrm{p}=0.007)$.

\section{Discussion}

The correlates of left extinction produced by a right hemispheric stroke and assessed by CT are not confined to cortical lesions involving the parietal cortex, as traditionally maintained. ${ }^{27}$ In about $50 \%$ of the patients deep structures are damaged. In the cortico-subcortical group the parieto-occipital regions are involved in about $40 \%$ of the patients, but instances of frontal damage are also found.

Single case reports of left visual or tactile extinction in patients with right sided deep lesions have been published. ${ }^{25}$ Our study is, however, the first large anatomoclinical study showing a close association of tactile and visual extinction with subcortical damage. Ferro et al found visual extinction, tactile extinction, or both in four out of $15(27 \%)$ patients with right subcortical infarcts involving the basal ganglia or the white matter. ${ }^{26}$ Single case reports also suggest a possible association of subcortical damage with contralateral auditory extinction. ${ }^{1326-29}$ In the group study of De Renzi et al, six of 15 patients $(40 \%)$ with long lasting auditory extinction had subcortical lenticular lesions. ${ }^{22}$

The lesion pattern of visual and tactile extinction may be compared with the 
anatomical findings in patients with neglect. ${ }^{16}$ Extinction and neglect are similar in that both deficits may be produced by various cortical and subcortical lesions. This finding is by and large in line with current views that higher brain functions such as perceptual representation and awareness of extrapersonal space and body are mediated by complex neural circuits and suggests that a single deficit underlies extinction and neglect. ${ }^{17}{ }^{25} \mathrm{~A}$ major difference was found, however. Over $50 \%$ of patients with extinction not associated with neglect had lesions confined to deep structures. By contrast, only about $25 \%$ of patients with neglect without extinction had subcortical damage. Hier et al, with a clinical non-quantitative examination, found significant correlations of left tactile extinction with lesion size in the deep structures of the right hemisphere and in the right parietal and temporal lobes, whereas left neglect was significantly related only with lesion size in the right parietal lobe. ${ }^{30}$

In most patients with extinction produced by deep lesions both the grey nuclei and the internal capsule or the periventricular white matter were damaged (see table 2). These sites, together with the high incidence of subcortical lesions in patients with extinction, are compatible with the view that the disorder may be produced, at least in part, by defective processing of contralateral sensory stimuli. ${ }^{131}$ The association of extinction with subcortical lesions involving, among other structures, the ascending sensory pathways, may be readily accounted for by a sensory interpretation. The absence in the present series of patients with lesions confined to the anterior limb of the internal capsule, which does not convey sensory input to the cortex, corroborates this conclusion. By contrast, the few published cases with selective damage of the anterior limb have motor neglect and motor extinction whereas visual and tactile extinction are remarkably absent. ${ }^{32} 33$

In line with the view that extinction has a sensory component, in the group with deep damage (table 2) five of the 18 patients without hemineglect $(28 \%)$ had small lesions confined to the white matter, the internal capsule, or both, sparing the grey nuclei. Conversely, all six patients with associated neglect (table 2) had lesions also involving the basal ganglia or the thalamus, and the overall frequency of white matter lesions in patients with neglect was $12 \%$ (two of 17 cases, see tables 2 and 3 ). Similarly, in Vallar and Perani's series, only one of 19 patients $(5 \%)$ with lesions confined to the white matter, internal capsule or both showed hemineglect, which, in turn, was found in 12 of the 32 patients (38\%) with lesions involving also the grey nuclei. ${ }^{23}$ In patients with deep lesions, thalamic damage seems to be a main feature distinguishing the anatomical correlates of neglect from those of extinction. The frequency of thalamic lesions was $6 \%$ (one out of 18 cases, table 2 ) in patients with extinction without neglect, and $47 \%$ (eight out of 17 cases, tables 2 and 3 ) when neglect was present. This finding, together with the common involvement of the posterior limb of the internal capsule in neglect patients, supports the view that a circuit comprising as main components the posterior-inferior parietal cortex and the posterior thalamus is a main neural basis of the internal representation of extrapersonal space disrupted in neglect. ${ }^{25}$

The sensory interpretation of extinction is also supported by the lesion patterns in the patients with cortico-subcortical damage. The most often damaged regions included the rolandic (sensory-motor) cortex and the paraventricular occipital area, which comprises the optic radiation. ${ }^{34}$ By contrast, when extinction was associated with hemineglect, the supramarginal gyrus in the inferior parietal lobule was the most often damaged region, in line with previous findings. 151623

In four patients with extinction without neglect $(5,9,11,14$, table 2$)$ the subcortical lesion was confined to the lenticular region, with no, or minimal, detectable involvement of the internal capsule and the white matter. Similarly, auditory extinction has been reported in a few patients with caudate or lenticular infarcts not involving capsular or white matter fibre tracts. ${ }^{26}$ The somatosensory and visual cortical areas, and the association areas of the parietal cortex send widespread projections to the putamen and the caudate nuclei. ${ }^{35}$ One possible role of these connections may concern the preparation of motor responses to sensory stimuli. In the rat, the pharmacologically induced depletion of striatal dopamine yields a severe neglect disorder, including visual extinction, which is due to the defective organisation of a motor response, rather than to sensory factors. ${ }^{36}{ }^{37}$ In patients with right-brain damage detection of single contralesional visual stimuli and visual extinction are worsened when a motor response is required. ${ }^{6}$ These findings suggest that extinction may also have a non-sensory component, possibly related to output factors. Also, the occurrence of extinction in patients with frontal lesions may be related to nonsensory factors.

Tactile and visual extinction do not necessarily co-occur in the individual patient. In the present series only 10 of 46 patients (22\%) showed both tactile and visual extinction (see table 1). Similarly, the presence of visual extinction is not related to auditory extinction. ${ }^{22} 38$ The existence of sensory, modalityspecific, components of extinction may readily account for these dissociations. Also hemineglect and extinction may not co-occur. ${ }^{1823}$ In the present series, neglect was found only in 13 of $46(28 \%)$ patients with extinction and no patient with bimodal extinction (tactile and visual) showed visuospatial neglect.

In this study the site of the cerebral damage has been localised by CT scan. The area of functional derangement produced by a focal lesion, however, also involves structurally undamaged, far removed, connected regions. ${ }^{39}$ In patients with right-brain damage and with neglect and subcortical lesions cortical hypoperfusion and hypometabolism 
have been found. ${ }^{4041}$ Autoradiographic studies in monkeys with extinction produced by focal cortical lesions have shown hypometabolism in subcortical, structurally undamaged, connected structures. ${ }^{42}$ In both humans and monkeys recovery parallels regression of hypometabolism and hypoperfusion. ${ }^{41-43}$ These findings, together with the various lesion sites associated with extinction and neglect, are consistent with the view that the normal operation of spatial-perceptual functions is subserved by neural circuits comprising both cortical and subcortical structures and their connections. ${ }^{25}$ The patterns of association of the lesion sites in patients with extinction and neglect as assessed by CT do not overlap, however. This suggests that the two disorders may be produced by the dysfunction of different cortico-subcortical circuits.

The present study suggests therefore, from an anatomical perspective, that extinction and visuospatial hemineglect are likely to be discrete neurological disorders, with different underlying mechanisms and neural correlates, rather than manifestations of a single deficit. ${ }^{17}$ Neglect may be conceived as a derangement of internal representations (for example, perceptual and premotor) of egocentric space. ${ }^{44-46}$ Its neural correlates include as main components the posterior parietal and premotor cortices. ${ }^{1647}$ The clinical phenomenon of extinction, by contrast, may be fractionated into two component deficits. A central impairment may reflect the damage of perceptual (possibly modality-specific) and response mechanisms. ${ }^{64-50}$ The anatomical correlates of these deficits may be closely related to those of hemineglect, ${ }^{1647}$ accounting for the association between extinction, hemineglect, and right-brain damage. A sensory, modalityspecific, component may be due to the defective processing of information contralateral to the lesion. ${ }^{31}$ In patients with extinction in the absence of hemineglect the relatively high incidence of subcortical lesions involving the white matter fibre tracts may be a main anatomical correlate of the sensory component of extinction.

This study has been supported in part by CNR and MURST grants. We are grateful to Paolo Elli, for his helpful suggestions.

1 Wortis SB, Bender MB, Teuber H-L. The significance of the phenomenon of extinction. $\mathcal{F}$ Nerv Ment Dis 1948 ; 107:382-7.

2 Critchley $M$. The phenomenon of tactile inattention with special reference to parietal lesions. Brain 1949;72: 538-61.

3 Schwartz AS, Marchok PL, Flynn RE. A sensitive test for tactile extinction: results in patients with parietal and
frontal lobe disease. $\mathcal{F}$ Neurol Neurosurg Psychiatry 1977 ; 40:228-33.

4 Gainotti G, De Bonis C, Daniele A, Caltagirone C. Contralateral and ipsilateral tactile extinction in patients with right and left focal brain damage. Int $\mathcal{F}$ Neurosci with right and

5 Meador KJ, Loring DW, Lee GP, et al. Right cerebral specialization for tactile attention as evidenced by intracarotid sodium amytal. Neurology 1988;38:1763-6.

6 Bisiach E, Vallar G, Geminiani G. Influence of response modality on perceptual awareness of contralesional visual stimuli. Brain 1989;112:1627-36.
7 Critchley M. The parietal lobes. New York: Hafner Press, 1953.

8 Heilman KM, Valenstein E. Auditory neglect in man. Arch Neurol 1972;26:32-5.

9 Heilman KM, Valenstein E. Frontal lobe neglect in man. Neurology 1972;22:660-4.

10 Watson RT, Heilman KM. Thalamic neglect. Neurology 1979;29:690-4.

11 Cambier J, Elghozi D, Strube E. Lesion du thalamus droit avec syndrome de l'hemisphere mineur. Discussion du concept de negligence thalamique. Rev Neurol 1980; 136:105-16.

12 Stein S, Volpe BT. Classical "parietal" neglect syndrome after subcortical right frontal lobe infarction. Neurology 1983;33:797-9.

13 Cambier J, Graveleau P, Decroix JP, Elghozi D, Masson M. La syndrome de l'artere choroidienne anterieure: etude neuropsychologique de 4 cas. Rev Neurol 1983; 139:553-9.

14 Brain WR. Visual disorientation with special reference to lesions of the right cerebral hemisphere. Brain 1941; 64:244-72.

15 Hecaen H, Penfield W, Bertrand C, Malmo R. The syndrome of apractognosia due to lesions of the minor cerebral hemisphere. Arch Neurol Psychiatry 1956;75: 400-34.

16 Vallar G, Perani D. The anatomy of spatial neglect in humans. In: Jeannerod $\mathbf{M}$, ed. Neurophysiological and neuropsychological aspects of spatial neglect. Amsterdam Elsevier, 1987:235-58.

17 Heilman KM, Watson RT, Valenstein E. Neglect and related disorders. In: Heilman KM, Valenstein E, eds Clinical neuropsychology. 2nd ed. Oxford: Oxford University Press, 1985:243-93.

18 Bisiach E, Vallar G, Perani D, Papagno C, Berti A Unawareness of disease following lesions of the right hemisphere: anosognosia for hemiplegia and anosognosia for hemianopia. Neuropsychologia 1986; 24:471-82.

19 Damasio H, Damasio AR. Lesion analysis in neuro psychology. New York: Oxford University Press, 1989.

20 Matsui T, Hirano A. An atlas of the human brain for computerised tomography. Tokyo: Igaku-Shoin, 1978.

21 Kertesz A, Harlock W, Coates R. Computer tomographic localization, lesion size, and prognosis in aphasia and
lates nonverbal impairment. Brain Lang 1979;8:34-50.

22 De Renzi E, Gentilini M, Pattacini F. Auditory extinction following hemisphere damage. Neuropsychologia 1984; 22:733-44.

23 Vallar G, Perani D. The anatomy of unilateral neglect after right hemisphere stroke lesions. A clinical CT/Scan correlation study in man. Neuropsychologia 1986;24: 609-22.

24 Cappa SF, Guariglia C, Messa C, Zoccolotti P, Pizzamiglio L. Computed tomography correlates of chronic unilateral neglect. Neuropsychology 1991;5: 195-204.

25 Cappa SF, Vallar G. Neuropsychological disorders after subcortical lesions: implications for neural models of language and spatial attention. In: Vallar G, Cappa SF Wallesch C-W, eds. Neuropsychological disorders associated with subcortical lesions. Oxford: Oxford University Press, with subcortical

26 Ferro JM, Kertesz A, Black S. Subcortical neglect: quantitation, anatomy, and recovery. Neurology 1987;37 1487-92.

27 Watson RT, Valenstein E, Heilman KM. Thalamic neglect. Possible role of the medial thalamus and nucleus reticularis in behavior. Arch Neurol 1981;38 501-6.

28 Castro-Caldas A, Guerreiro M, Confraria A. Transient and persistent right ear extinction in dichotic listening: subcortical lesions. Neurology 1984;34:1418-22.

29 Pasquier F, Leys D, Steinling M, Guieu JD, Petit H, Cambier J. Agnosie uditive unilaterale droite consecutive a une hemorragie lenticulare gauche. Rev Neurol a une hemorragie.

30 Hier DB, Mondlock J, Caplan LR. Recovery of behavioral abnormalities after right hemisphere stroke. Neurology 1983;33:345-50.

31 Birch HG, Belmont I, Karp E. Delayed information processing and extinction following brain damage. Brain 1967;90:113-30.

32 Viader F, Cambier J, Pariser P. Phenomene d'extinction motrice gauche. Lesion ischemique du bras anterieur de la capsule interne. Rev Neurol 1982;138:213-17.

33 de la Sayette V, Bouvard G, Eustache F, Chapon F, Rivaton F, Viader F, Lechevalier B. Infarct of the anterior limb of the right internal capsule causing left motor neglect: case report and cerebral blood flow study. Cortex 1989;25:147-54.

34 Garey LJ. Visual system. In: Paxinos G, ed. The human nervous system. New York: Academic Press, 1990: 945-77.

35 Alheid GF, Heimer L. Basal ganglia. In: Paxinos G. ed. The human nervous system. New York: Academic Press, 1990:483-582.

36 Brown VJ, Robbins TW. Deficit in response space following unilateral striatal dopamine depletion in the rat. $\mathcal{F}$ Neurosci 1989;9:983-9.

37 Carli M, Jones GH, Robbins TW. Effects of unilateral dorsal and ventral striatal dopamine depletion on visual neglect in the rat: a neural and behavioural analysis Neuroscience 1989;29:309-27. 
38 Sieroff E, Michel F. Verbal visual extinction in right/left hemisphere lesion patients and the problem of lexical access. Neuropsychologia 1987;25:919-33.

39 Feeney DM, Baron, J-C. Diaschisis. Stroke 1986;17: 817-30.

40 Perani D, Vallar G, Cappa SF, Messa C, Fazio F. Aphasia and neglect after subcortical stroke. Brain 1987; 110:1211-229.

41 Perani D, Vallar G, Paulesu E, Alberoni M, Fazio F. Left and right hemisphere contribution to recovery from neglect after right hemisphere damage. A $\left[{ }^{18} \mathrm{~F}\right]$ FDG

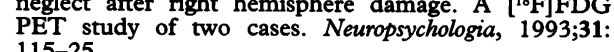

Deuel RK. Neural dysfunction during hemineglect after
cortical damage in two monkey models. In: Jeannerod $M$, ed. Neurophysiological and neuropsychological aspects of spatial neglect. Amsterdam: Elsevier, 1987:315-44.

43 Vallar G, Perani D, Cappa SF, Messa C, Lenzi GL, Fazio F. Recovery from aphasia and neglect after subcortical stroke. ₹ Neurol Neurosurg Psychiatry 1988;51:1269-76. and premotor factors of unilateral neglect. Neurology 1990;40:1278-81.

45 Bottini G, Sterzi R, Vallar G. Directional hypokinesia in spatial hemineglect. $\mathcal{f}$ Neurol Neurosurg Psychiatry 1992;55:431-6.

46 Tegner $R$, Levander $M$. Through a looking glass: a new technique to demonstrate directional hypokinesia in unilateral neglect. Brain 1991;114:1943-51.

47 Vallar $G$. The anatomical basis of spatial hemineglect in humans. In Robertson IH and Marshall JC, eds. Unilateral neglect: clinical and experimental studies. Howe, Sussex: Lawrence Erlbaum, 1993:27-59.

48 Kaplan RF, Verfaellie M, DeWitt LD, Caplan LR. Effects of changes in stimulus contingency on visual extinction Neurology 1990;40:1299-301.

49 Vallar G, Bottini G, Rusconi ML, Sterzi R. Exploring somatosensory hemineglect by vestibular stimulation. Brain 1993;116:71-86.

50 Inhoff AW, Rafal RD, Posner MI. Bimodal extinction without cross-modal extinction. $f$ Neurol Neurosurg Psychiatry 1992;55:36-9. 